\title{
The determination of effective concentration of acethonilic Ipomoea cairica leaves extract against laboratory and field strains of Aedes albopictus and Aedes aegypti mosquito larvae
}

\author{
Rodzay, R. ${ }^{1}$, Zuharah, W.F. ${ }^{1,2 *}$ \\ ${ }^{1}$ School of Biological Sciences, Universiti Sains Malaysia, 11800 Minden, Penang, Malaysia \\ ${ }^{2}$ Vector Control Research Unit, School of Biological Sciences, Universiti Sains Malaysia, 11800 Minden, Penang, Malaysia \\ *Corresponding author: wfatma@usm.my
}

\section{ARTICLE HISTORY}

Received: 2 April 2020

Revised: 5 March 2021

Accepted: 17 August 2021

Published: 30 September 2021

\begin{abstract}
Inundated with escalating dengue outbreaks, there is an urgent call to find alternate potential vector control methods as the currently employed method fails to curb the expanding of dengue virus transmission in Malaysia. Supported by this aim, we are interested in exploiting the potential of Ipomoea cairica leaves extract towards primary and secondary vectors of dengue fever, Aedes aegypti and Aedes albopictus. To assess the effectiveness of this plant extracts towards Aedes larvae, we carried out two complementary analyses. First, we observed the comparative effectiveness of larvicidal activity I. cairica extract against the laboratory and field strains of Ae. aegypti and Ae. albopictus. Then, we determined the effective lethal dose of this plant extract against Aedes larvae using log-probit regression analysis of the SPSS 20.0 programme. Results from bioassay demonstrated that $I$. cairica leaves extract was highly effective to induce larvicidal mortality of Ae. albopictus and Ae. aegypti within 24 and 48 hours post-treatment. Results from the factorial analysis of variance (ANOVA) also indicated that there were significant differences in larvicidal activity between species and strains used $(P<0.05)$. It is interesting to notify that the sequence of effectiveness for the larvicidal activities of $I$. cairica acethonilic leaves extract is in the manner; Ae. albopictus field strain $>A e$. aegypti laboratory strain $>A e$. aegypti field strain $>A e$. albopictus laboratory strain. The I. cairica leaves extract displayed high larvicidal activity against Ae. albopictus as compared to $A$ e. aegypti. This is the first evaluation involving the comparison of $I$. cairica leaves extract effects for the laboratory strain and field strain of Ae. albopictus and Ae. aegypti.
\end{abstract}

Keywords: Aedes albopictus; Aedes aegypti; biological control; plant extracts; Ipomoea cairica.

\section{INTRODUCTION}

Over the last five decades, the cycles of dengue avenues have increased dramatically with a 30 fold global incidence expanding geographically into many previously unaffected areas (WHO 2009). In an attempt to ward off epidemiology of dengue virus, a series of insecticide discoveries have been developed since the late 1930 s as tools for mosquito control approaches (Becker et al., 2003). Due to the widespread of insecticide resistance, the control of the mosquito vector population currently had turned into a failure (Hasan et al., 2016) and insecticide resistance management is crucial (Dusfour, 2019). This factor has shifted researchers' attention on developing other alternative controls, including biological controls (Frentiu et al., 2014) as a very promising method to reduce the transmission of dengue whilst pose no risk to human health and the environments.
The recognition of mosquitocidal compounds in plant extracts has called many research to test the potential of phytochemicals as one of potential candidatures in biological control of Aedes mosquitoes. The compounds within plant parts such as phenolics, terpenoids, flavonoids and alkaloids have been proven to induce larvicidal and adulticidal properties (Elumalai et al., 2012). According to Alouni et al. (2009), results from phytochemicals studies could undoubtedly reduce the rampant usage of chemical insecticides and increase the opportunity of botanical pesticides for biological control of medically important vectors.

Research thrusts have focused on studying phytochemicals derived from genus Ipomoea since 1950s (Meira et al., 2012). Ipomoea cairica is diverging species from Family Convolvulacea, which commonly known as 'Railway creeper' due to their twining characteristics (Austin \& Huáman, 1996; 
Thiagaletchumi et al., 2014). The major constituents of I. cairica extracts consist of alkaloids, sterols, flavonoids, reducing sugars, tannins, saponins, terpenoids, anthraquinones, glycosides and phenols properties which could exhibit cytotoxic activity (Ralte, 2014).

Thomas et al. (2004) revealed the larvicidal efficacy of $I$. cairica essential oils could induce $100 \%$ mortality against four medically important vectors, Culex tritaeniorhynchus, Ae. aegypti, Anopheles stephensi and Culex quinquefasciatus at very low concentrations. The high potential of $I$. cairica as biolarvicidal agents were also proven against key dengue vectors, Ae. aegypti and Ae. albopictus. Results of these studies revealed the leaves part of $I$. cairica exhibited the strongest larvicidal activities against both principal vectors of dengue virus at low concentrations of $\mathrm{LC}_{50}$ and $\mathrm{LC}_{95}$ at $105.59 \mathrm{ppm}$ and $321.56 \mathrm{ppm}$ for Ae. albopictus, while for Ae. aegypti were at $101.94 \mathrm{ppm}$ and $447.78 \mathrm{ppm}$, respectively (Ahbirami et al., 2014).

Complementing the need for biological control agents as alternative tools for mosquito controls in Malaysia, we are interested in determining the effective lethal concentration of $I$. cairica against Ae. albopictus and Ae. aegypti larvae. In this study, we compared the baseline concentration and the susceptibility of both Vector Control Research Unit (VCRU) laboratory and field strains of Aedes mosquitoes from urban and sub-urban regions in Penang towards I. cairica.

\section{MATERIALS AND METHODS}

\section{Mosquito samples and rearing}

Two sampling sites were chosen in this study. Aedes aegypti field strain was collected from a small urban residential area in Sungai Dua consisted of apartments and commercial areas (N 5.348508, E 100.300104) and known as dengue hotspot area (Mohiddin et al., 2015). While Ae. albopictus field strain was collected from a sub-urban area in Batu Maung (N5.283881, E100.279320) where this area surrounded by vegetation, playground and landed houses. Both sites were chosen due to the dominancy of Ae. aegypti and Ae. albopictus population within the respected area. In this study, we used F1 larvae of field strain mosquitoes. Two weeks prior to the experiment, eggs of both Aedes species were obtained by placing ovitraps with soaked paddles inside as an oviposition substrate in the selected sites. The collected larvae were reared in enamel trays contained with dechlorinated water and fed daily with $0.5 \mathrm{gm}$ larval food made of dog biscuits, beef liver, yeast and milk powder at the ratio of $2: 1: 1: 1$. The larval culture was maintained at a temperature of $28 \pm 2{ }^{\circ} \mathrm{C}$ and $70-85 \%$ humidity. After emergence, both adult Aedes species were morphologically identified to species using the taxonomic key by Becker et al. (2003). The emergence of colonies confirmed their dominancy within their respective areas. In order to ensure the uniformity of the larvae stage used in bioassays, we used newly hatched F1 larvae after the separation of adults at F0 generation collected from the fields. The larvae were reared and maintained until they reached a suitable stage for the continuation of bioassays.

Laboratory strains of Ae. aegypti and Ae. albopictus established by Vector Control Research Unit (VCRU), School of Biological Sciences, Universiti Sains Malaysia since 1970s were used in this study as the baseline susceptible strain. The eggs batches of the F1 generation were hatched in enamel trays soaked with dechlorinated water and maintained using the same procedures for field strain Aedes larvae mentioned above. All larvae strains and species were reared until the late third instar larva (L3), and early fourth instar larva (L4) stages before being subjected to bioassays test.

\section{Collections and Preparations of Ipomoea cairica leaves}

Fresh I. cairica leaves were collected around Sungai Dua area $\left(\mathrm{N} 5^{\circ} .351981, \mathrm{E} 100^{\circ} .298572\right)$ Penang Island. As the leaves part of $I$. cairica showed the most remarkable larvicidal activities (Ahbirami et al., 2014), only leaves parts of this plant were segregated for the extraction preparations. The collected plants were identified and authenticated by a plant taxonomist from Herbarium Unit, Universiti Sains Malaysia. I. cairica leaves were air-dried until a constant weight was achieved for one to two weeks at room temperature condition. The dried leaves were mechanically ground into fine powders using a commercial electrical stainless-steel blender (Panasonic: MX-899TM).

\section{Ipomoea cairica Soxhlet extraction}

Ipomoea cairica leaves were extracted with Soxhlet apparatus using acetone as the solvent. As solvents influence the polarity of organic compounds are influenced by solvents, acetone was chosen as the crude solvents in this study due to their established reactions with I. cairica leaves (Ahbirami et al., 2014). A total of $40 \mathrm{~g}$ powdered I. cairica leaves were weighed using an analytical balance and inserted into a Soxhlet extraction thimble. Pebbles were added to optimize the flowing of solvent passing through the plant powder within extraction cycles. The thimble filled with plant powder was capped with cotton wool and loaded into the Soxhlet extractor. $2 \mathrm{~L}$ of acetone solvent was filled into round-bottom flask placed on the heating mantle. The boiling point for acetone extraction was set up at $50.5^{\circ} \mathrm{C}$. The extraction cycles were run for 3 hours with a few flushing until the colour of solvent in the siphon side arms turned to almost clear. The procedure was repeated using different $40 \mathrm{~g}$ plant powder for each round. The excess solvent within round-bottom flask was loaded into several Petri dishes. Then, the Petri dishes were transferred to the oven at $37^{\circ} \mathrm{C}$ for drying purposes.

\section{Stocks solution and serial concentrations preparation}

To prepare the stock solutions, one gram of crude extract yield was weighed using an analytical balance. The weighed solid residues were then dissolved in $100 \mathrm{~mL}$ acetone to make up 10,000 ppm stock solutions. From prepared stock solutions, serial dilutions were then prepared by adding specific amounts of plant extracts from the stock solution into distilled water to get desired concentrations for the assay. The remaining stock solutions were kept in a refrigerator at $4^{\circ} \mathrm{C}$ until further used.

\section{Larvicidal bioassay using Ipomoea cairica extract}

The larvicidal bioassays for determining the effective activities of $I$. cairica extraction was run following the World Health Organization guidelines of mosquito larvicides (WHO, 2005). Twenty late third and early fourth instar larvae were introduced into testing cups filled with a $200 \mathrm{~mL}$ desired range of concentrations. A total of 12 concentrations were tested separately for each species and strains at $10 \mathrm{ppm}, 30$ ppm, 50 ppm, 70 ppm, 80 ppm, 100 ppm, 120 ppm, 150 ppm, $200 \mathrm{pmm}, 300 \mathrm{ppm}, 400 \mathrm{ppm}$ and $500 \mathrm{ppm}$ given a range of $0 \%$ to $100 \%$ mortality. Each concentration set was replicated three times. The control set consisted of $199 \mathrm{ml}$ of distilled water added with $1 \mathrm{ml}$ of $10 \%$ acetone. Throughout the testing period, no larvae food was offered (Ishak et al., 2014; Samuel et al., 2014) due to not disrupting the infection process through oral intake of $I$. cairica particles. After $24 \mathrm{~h}$ and $48 \mathrm{~h}$ exposure, the larval mortality was observed and recorded. Dead larvae 
were identified as motionless larvae after probing with a needle in the siphon or cervical region (WHO, 2005).

\section{Statistical Analysis}

Statistical analysis was carried out to determine the lethal concentration (LC) and significant effects among the strains and species used subject to larval mortality. The efficacy of I. cairica extracts was determined using the $\mathrm{LC}_{50}$ and $\mathrm{LC}_{95}$ value, analyzed using log-probit regression analysis at $95 \%$ confidence interval in SPSS 20.0 programme. To detect the significant differences between different strains of Aedes species after the exposure to I. cairica extract, the factorial analysis of variance (ANOVA) was conducted. Prior to analysis, all the data were tested for normality (ShapiroWilk) to fulfil the assumption of ANOVA. Degree of concentrations, Aedes mosquito species and strains were subjected as fixed factors, whereas the larval mortality was considered as dependent variables. The level of significant differences for the statistical analyses was set at $\mathrm{P}<0.05$.

\section{RESULTS}

\section{Larvicidal effect of Ipomoea cairica against Aedes larvae}

After 24 hours post-treatment, it was observed that the mortality response at the highest concentration of $500 \mathrm{ppm}$ of both strains of Ae. albopictus has achieved $98 \%-100 \%$ mortality (Figure 1A), whereas, for Ae. aegypti, the mortality response of both strains were slightly lower, which were between $78 \%$ to $100 \%$ mortality (Figure 1C). In this study, larvicidal activity exhibited by $I$. cairica extracts towards Ae. albopictus were significantly higher than Ae. aegypti $(\mathrm{F}=7.656, d f=1, \mathrm{P}<0.05$; Table 1$)$. With respect to larval strains, the field strain of Ae. albopictus and laboratory strain of $A e$. aegypti showed a faster mortality response as compared to others (Figures $1 \mathrm{~A} \& \mathrm{C}$ ) and was found to be statistically significant between each strain $(\mathrm{F}=5.513, d f=1, \mathrm{P}<0.05$; Table 1). Both field strain of Ae. albopictus and laboratory strain of Ae. aegypti achieved $100 \%$ larval mortality after 24 hours posttreatment. Whereas laboratory strain of Ae. albopictus and field strain of Ae. aegypti were late in achieving $100 \%$ mortality and happened only after 48 hours post-treatment. As shown in Figure 1 , the bioactivity potential of $I$. cairica was varied significantly for each concentration $(\mathrm{F}=71.921, d f=12, \mathrm{P}<0.05$; Table 1). Maximum larval mortality observed in the promoted concentrations ranged from $300 \mathrm{ppm}-500 \mathrm{ppm}$ to achieve $100 \%$ larval mortality within the treated period (Figure 1). No mortality was notified in control treatments.

The effective lethal dose of Ipomoea cairica against Aedes larvae In this study, the $\mathrm{LC}_{50}$ of $I$. cairica leaves extracts treated against both Aedes larvae ranged between 31.85 ppm until 251.71 ppm. Whereas, $\mathrm{LC}_{95}$ values ranged between $121.57 \mathrm{ppm}$ until $1613.00 \mathrm{ppm}$. After $24 \mathrm{~h}$, it was observed that the probit values of Ae. albopictus laboratory strain ( $\mathrm{LC}_{50}$ : $251.71 \mathrm{ppm}$; $\mathrm{LC}_{95}$ : $1613.00 \mathrm{ppm}$; Table 2) were higher than those for the field strain ( $\mathrm{LC}_{50}$ : $53.46 \mathrm{ppm}$; LC $\mathrm{C}_{95}: 307.01 \mathrm{ppm}$; Table 2). In contrast for Ae. aegypti larvae, the lowest $\mathrm{LC}_{50}$ and $\mathrm{LC}_{95}$ values obtained after $24 \mathrm{~h}$ for the laboratory strain (LC $50: 124.17 \mathrm{ppm} ; \mathrm{LC}_{95}: 728.18$
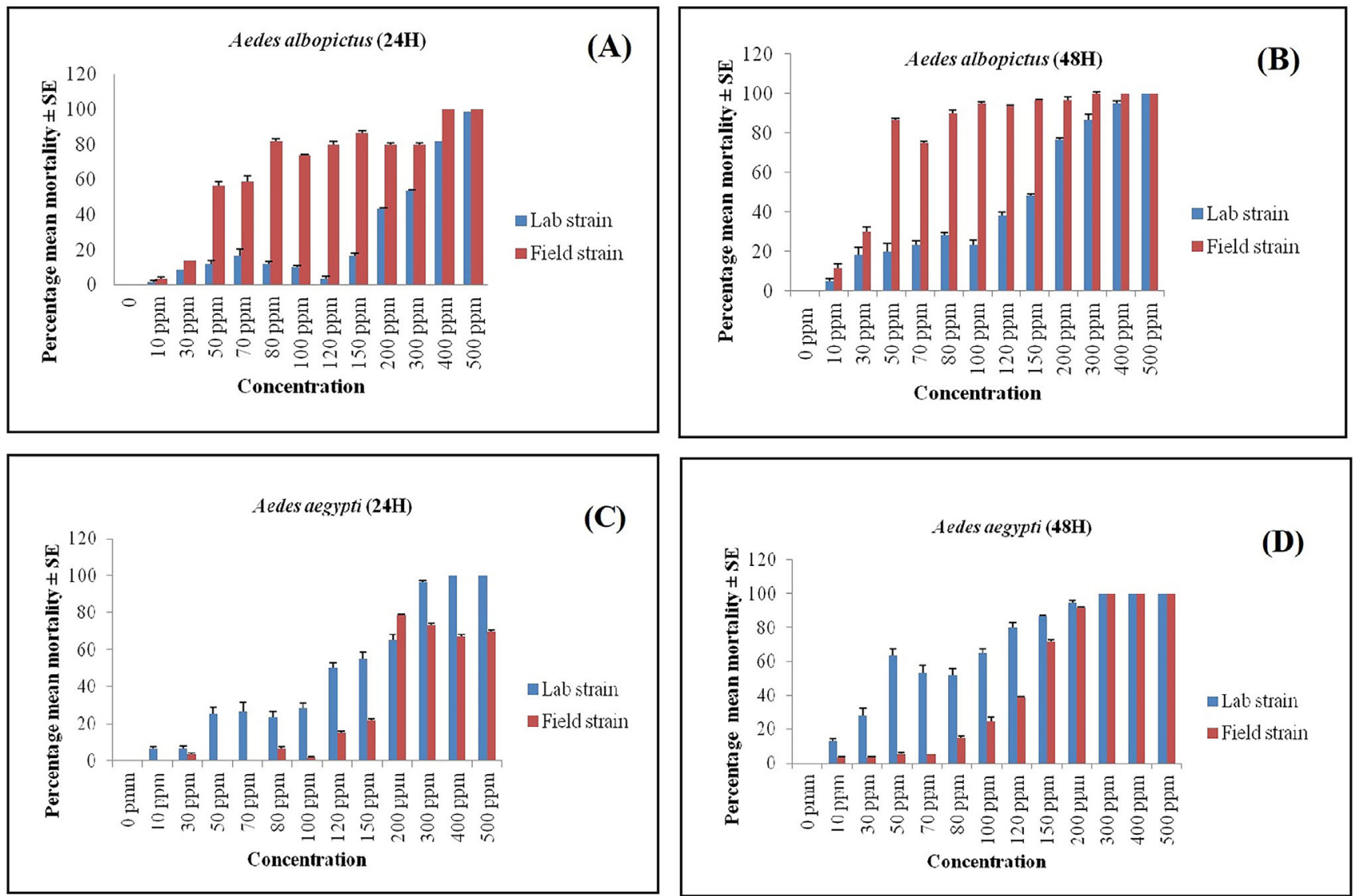

Figure 1. Mean percentage of Aedes larval mortality of; (A) Aedes albopictus at 24 hours post-treatment, (B) Aedes albopictus at 48 hours post-treatment, (C) Aedes aegypti at 24 hours post-treatment, and (D) Aedes aegypti at 48 hours post-treatment after exposure to different concentrations of Ipomoea cairica extract. 
Table 1. Results from factorial analysis of variance (ANOVA) on the effect of larvae species, strains, days and serial conidial concentrations on larval mortality. Significant values are in bold. Data were log transformed prior to analysis

\begin{tabular}{|c|c|c|c|c|}
\hline Source & $d f$ & Mean & $\begin{array}{l}\text { F-value } \\
\text { Square }\end{array}$ & $P$-value \\
\hline Aedes species (A.S) & 1 & 4.119 & 7.656 & $0.006 *$ \\
\hline Strain $(S)$ & 1 & 2.966 & 5.513 & $0.020 *$ \\
\hline Hours $(\mathrm{H})$ & 1 & 18.350 & 34.106 & $0.000^{*}$ \\
\hline Concentration (C) & 12 & 38.696 & 71.921 & $0.000 *$ \\
\hline A.S*S & 1 & 61.834 & 114.926 & $0.000 *$ \\
\hline A.S*H & 1 & 0.133 & 0.247 & 0.620 \\
\hline A.S*C & 12 & 1.541 & 2.863 & $0.001 *$ \\
\hline $\mathrm{S}^{*} \mathrm{H}$ & 1 & 2.107 & 3.916 & $0.049 *$ \\
\hline $\mathrm{S}^{*} \mathrm{C}$ & 12 & 0.574 & 1.066 & 0.390 \\
\hline $\mathrm{H}^{*} \mathrm{C}$ & 12 & 0.583 & 1.084 & 0.375 \\
\hline A.S*S*H & 1 & 0.029 & 0.054 & 0.816 \\
\hline A.S*S*C & 12 & 3.430 & 6.374 & $0.000 *$ \\
\hline A.S*H*C & 12 & 0.241 & 0.448 & 0.942 \\
\hline $\mathrm{S}^{*} \mathrm{H}^{*} \mathrm{C}$ & 12 & 0.272 & 0.506 & 0.910 \\
\hline A.S*S*H*C & 12 & 0.469 & 0.871 & 0.577 \\
\hline
\end{tabular}

ppm; Table 2) as compared to the field strain ( $\mathrm{LC}_{50}: 227.82$ ppm; $\mathrm{LC}_{95}$ : 957.23 ppm; Table 2).

Referring to the probit analysis results, the order of larvicidal activity based on the $\mathrm{LC}_{50}$ and $\mathrm{LC}_{95}$ values and the effectiveness of $I$. cairica against both Aedes larvae were observed in the sequence of Ae. albopictus field strain $>A e$. aegypti laboratory strain $>A e$. aegypti field strain $>A e$. albopictus laboratory strain (Tables 2 and 3). Based on this observation, it is evident from our understanding to speculate that field strain of Ae. albopictus were the most susceptible to I. cairica treatment as compared to other strain of larvae.

\section{Deformities of Aedes larvae after Ipomoea cairica treatment}

The morphological deformities that occurred in the treated larvae pointed out the potent bioactivity of I. cairica against both Aedes larvae used in this study (Figure 2). The extract treatment has caused massive morphological disruption with darkening and blackening of the midgut epithelial layer under light microscopy (Figure 2A). Meanwhile, the normal control larvae used in this study still retained their structure integrity (Figure 2B).

Table 2. The effective lethal dose of Ipomoea cairica against laboratory and field strains Aedes albopictus and Aedes aegypti treated for 24 hours and 48 hours

\begin{tabular}{|c|c|c|c|c|c|}
\hline Species & Strain & Time (Hours) & $\mathrm{LC}_{50} \mathrm{ppm}$ & $\mathrm{LC}_{95} \mathrm{ppm}$ & Probit equation \\
\hline \multirow{4}{*}{ Aedes albopictus } & Laboratory & $24 \mathrm{H}$ & $251.71(181.18-450.25)$ & 1613.00 (746.15-10129.59) & $2.039 x-4.895$ \\
\hline & & $48 \mathrm{H}$ & 125.98 (93.09-179.89) & 745.50 (409.47-2738.78) & $2.130 x-4.474$ \\
\hline & Field & $24 \mathrm{H}$ & $53.46(37.31-67.18)$ & 307.01 (212.13-621.47) & $2.167 x-3.744$ \\
\hline & & $48 \mathrm{H}$ & $31.85(21.12-41.82)$ & 121.57 (86.25-231.75) & $2.827 x-4.250$ \\
\hline \multirow{4}{*}{ Aedes aegypti } & Laboratory & $24 \mathrm{H}$ & 124.17 (88.91-199.17) & 728.18 (359.92-4904.70) & $2.141 x-4.483$ \\
\hline & & $48 \mathrm{H}$ & $49.60(29.02-70.74)$ & 355.99 (194.23-1663.15) & $1.922 x-3.258$ \\
\hline & Field & $24 \mathrm{H}$ & $227.82(183.50-285.33)$ & $957.23(625.42-2256.56)$ & $2.638 x-6.220$ \\
\hline & & $48 \mathrm{H}$ & $124.52(112.45-140.62)$ & 242.82 (199.57-340.49) & $5.671 x-11.882$ \\
\hline
\end{tabular}

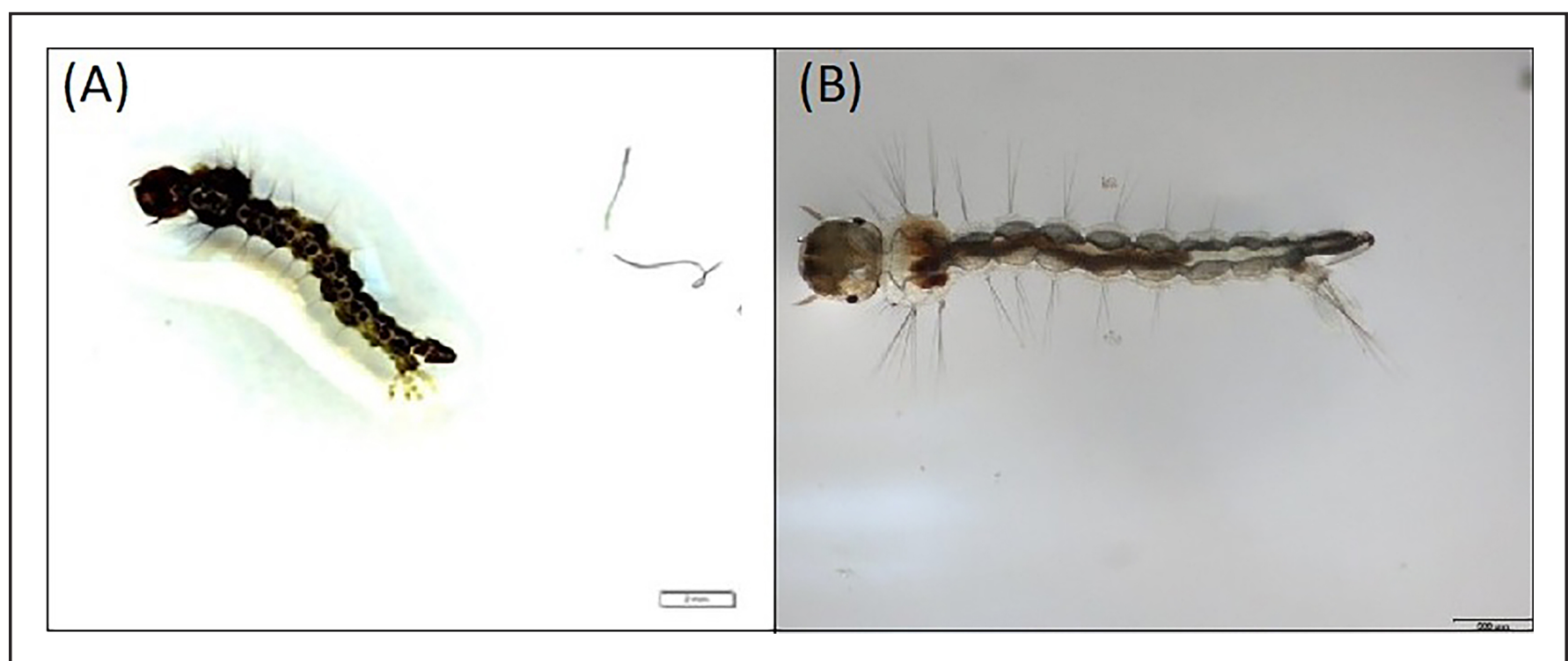

Figure 2. Morphological deformities exhibited by Ipomoea cairica leave extracts on treated larvae; (A) larvae with darkening abdomen, (B) normal larvae. 


\section{DISCUSSION}

Following the sequential discoveries of bioactivity of plant extracts against mosquitoes, here we demonstrated the biological potential of $I$. cairica leaves extracts towards the laboratory and field strains of both medically important vectors (Ae. albopictus and Ae. aegypti). Based on our study, we had found that the bioactivity of $I$. cairica leaves extracts caused can induce $100 \%$ larval mortality on both laboratory and field strains of Aedes larvae at as low as $300 \mathrm{ppm}$. It was found that the Ae. albopictus field strain is the most susceptible strain to $I$. cairica extract compared to other treated groups used in this study. Justifying the ability of $I$. cairica extracts to induce mosquito larvae, the effectiveness of I. cairica crude extracts against mosquito larvae have also been proven against $C_{x}$. tritaeniorhynchus, $C x$. quinquefasciatus, An. stephensi and Ae. aegypti in the previous study (Thomas et al., 2004). The results from the previous study and the present observation ratifying the potential of $I$. cairica as an alternative larvicide to fight off Aedes larvae in Malaysia.

In this study, the bioactivity of $I$. cairica leaves extracts showed various larvicidal activity reflecting upon the dosage of concentration being applied in the treatments. Naturally, the mortality rate was increased, corresponding to the rises in the concentration of the plant extracts used in the treatment (Samuel et al., 2014). Results of I. cairica larvicidal activity against Aedes larvae in this study also showed a positive correlation with the plant extracts concentration used. A similar trend was observed when the larvicidal properties of Knema attenuata extracts were tested against Ae. albopictus and An. stephensi, the mortality of the treated larvae showed was in a concentration-dependent manner. In facts, the geographical origin of the plant itself also plays important roles in the variation of phenolic composition and antioxidant activities of the plant extracts (Guo et al., 2011; Liu et al., 2018). Goa et al. (2011) indicated that the phenolic contents were influenced by growing conditions; where low temperature enhancing the synthesis of phenylalanine ammonia-lyase (PAL) in plants and may increase the production of phenolics, while high altitude and extended sunlight hours with higher UV radiation positively affect the activity of phenolics synthase (Kishore et al., 2010). Ishak et al. (2014) also showed a much lower concentration to cause $85 \%$ until $100 \%$ larvae mortality using I. cairica leaves extracts, even though those larvae were the same VCRU strain used in the current study. This hypothesizes that the bioactivity of plant extracts is influenced by the geographical origins of the plants and is associated with the dosage applied to the treatments.

The maximum efficacy of the plant extraction also depends upon the polarity of the solvents used to selectively extract the target phytochemical compounds (Samuel et al., 2014). The molecular affinity of polar solvent will extract polar molecules, whereas a non-polar solvent will extract non-polar molecules (Rawani et al., 2010). Since the polarity of our targeted compound are alkaloids and flavonoid, which usually performed using alcoholic solvent, we chose acetone as a solvent used in this present study. Besides, the preliminary information conducted by Ahbirami et al. (2014), also revealed the best solvent extract that is suitable to increase the bioactivity of $I$. cairica against Aedes larvae is acetone rather than methanol. This is due to the moderately low polarity index of acetone (5.1 indexes), which had conversely impacts on high efficacy of bioactivity of compounds which also had been proven in our results. The impact of solvent on the effectiveness of plant extract can be seen between our study and Ishak et al. (2014).
Despite finding the correct solvent to extract the active target molecules, selecting an appropriate solvent is also important to obtain the maximum yield of crude extract. As the physiochemical properties of acetone have a lower viscosity, the extraction using acetone as solvent could provide a better maximum high yield (Rathod \& Rathod, 2014), thus justifying acetone as a suitable solvent to be used in the present study.

The pattern of the mortality rate might be varied according to the larval species and strain. In this study, patterns of mortality rate observed on Ae. albopictus field strain showed faster larvicidal effect even at the slightest different amount of concentration being applied to the treatment. It was found that the $\mathrm{LC}_{50}$ and $\mathrm{LC}_{95}$ values obtained for Ae. albopictus field strain was the lowest, indicating a potent larvicidal effect of $I$. cairica leaf extracts towards this strain. The differences in the bioactivity of plant extracts towards different larval species and strain, possibly due to active ingredients of plant extracts that attack various aspects of the immune defence mechanism of the larvae which depends on their local adaptation. In this present study, the collected field strain of Ae. aegypti was from the urban area, whereas Ae. albopictus was from the sub-urban area. As Ae. aegypti predominantly live within or near to the house due to its selective preferences on human blood, the infestations of the dengue virus commonly occur within the urban area. Our selected study site for Ae. aegypti collection is Sungai Dua, Penang, which is known as one of the hotspot areas in Penang Island, Malaysia (Ritchie, 2014; Mohiddin et al., 2015). The extensive usage of insecticides during fogging activities in that area after cases notification probably has created insecticide resistance in Ae. aegypti population used in this study. A survey conducted by Sumayyah et al. (2016) to the residents living in Sungai Dua area reported that they currently experienced the effects of intense use of mosquito insecticide, which had lowered the mortality effect on mosquitoes within that area. This might probably explained that the lower susceptibility of field strain Ae. aegypti towards the current tested control method which using plant extracts rather than insecticides control since the population never been exposed to plant extracts.

Since then, the mode of action of these I. cairica leaves extract on mosquito larvae is still lacking. However, it is known that the phytochemical compounds in plant extracts are formed by the secondary metabolites mechanism, which potentially caused the toxic effects effect to the insect physiology in many ways (Ghosh et al., 2012; Ralte, 2014). In our study, we observed the morphological deformities formed in the treated Aedes larvae, such as having darkening and blackening at their abdomen. The observation made during the assay also showed abnormal motions of larvae such as coiling and convulsion at the bottom of treated containers. This abnormal motion showing the earlier symptoms of toxicant activity of $I$. cairica extract against Aedes larvae in the present study before death took place.

Results from the phytochemical screening of $I$. cairica extracts revealed that the presence of alkaloids, saponins, tannins, and flavonoids were detected in the leaves extract of I. cairica (Ishak et al., 2014). Tannins are one of the metabolite compounds that act as an inhibitor to prolinerich protein preventing the process of protein synthesis of the cell from taking place (Ralte, 2014), thus causing depression on growth-rate and inhibition of the digestive enzyme (Bennick, 2002). The digestive tract of most of the insects is lined with a peritrophic membrane which plays an important roles in the digestive process and provides the protection from invasion by viruses, bacteria and other 
pathogens (Liu et al., 2014). As the peritrophic membrane composed of chitin and proteins, the action of tannins present in the I. cairica leaves extract, it could possibly cause the disruption of peritrophic membrane formation inside the guts of Aedes larvae. This disruption could inhibit larval development and lead to mortality which probably explained the cause of larval mortality in the present study. Besides, another phytochemical constituent of plant extracts that could cause the toxin to Aedes larvae is alkaloids. Alkaloids are known to have a toxic effect on insects and vertebrates by affecting the Acetylcholinesterase (AChE) action. The inhibition of AChE will cause acetylcholine accumulation at the synaptic pathway, disturbing the nerve impulse transmission (Rattan, 2010). Corresponding to this event, the insects exposed to alkaloids will finally have a lack of coordination in their body systems (Hussein et al., 2018), including physiological stress (Muñoz, 2020) and eventually death, as observed in the recent study.

Despite many research being conducted to find the most bio-potential plant extracts to inhibit the mosquito larval development, however, up to our knowledge, there is still no comparative studies conducted on the effectiveness of this plant extract against both laboratory and field strains of Aedes larvae. Interestingly, the I. cairica leaves crude extract used in this study showed the effectiveness towards the field strain of Ae. albopictus and Ae. aegypti. Despite the different level of susceptibility in both Aedes larvae shown in this study, it is worth to note that $I$. cairica leaves extracts to have a high potential to serve as an alternative biolarvicidal agent. It is a bonus to discover that there is still available botanical origin that can be used as safer larvicides which may act as a suitable alternative product to ward off Aedes populations in Malaysia.

\section{ACKNOWLEDGEMENTS}

We thank the Vector Control Research Unit, Universiti Sains Malaysia, for supplying mosquito laboratory strain used in this study. We also like to thank Sumayyah Aminoddin and Izwan Effendy Ismail for their field assistance. Also, all assistance from fellow mates of Medical Entomology Laboratory and Tropical Mycology Laboratory. This study was funded by the Research University Grant USM (1001/ PBIOLOGI/8011066), Fundamental Research Grant Scheme, Ministry of Higher Education Malaysia (203/PBIOLOGI/ 6711629), and myBrain15 Ministry of Higher Education for postgraduate study of Rohaiyu Md Rodzay.

\section{Conflict of Interest}

The authors declare that there is no conflict of interest.

\section{REFERENCES}

Ahbirami, R., Zuharah, W.F., Thiagaletchumi, M., Subramaniam, S. \& Sundarasekar, J. (2014). Larvicidal efficacy of different plant parts of railway creeper, Ipomoea cairica Extract against dengue vector mosquitoes, Aedes albopictus (Diptera: Culicidae) and Aedes aegypti (Diptera: Culicidae). Journal of Insect Science 14: 180. https://doi.org/10.1093/ jisesa/ieu042

Alouni, A., Rehimi, N. \& Soltani, N. (2009). Larvidicidal activity of a neem tree extract (Azadirachtin) against mosquito larvae in the Republic of Algeria. Jordan Journal of Biological Sciences 2: 15-22.
Austin, D.F. \& Huáman, Z. (1996). A synopsis of Ipomoea (Convolvulaceae) in the Americas. Taxon 45: 3-38. https:// doi.org/10.2307/1222581

Becker, N., Zgomba, M., Petric, D., Dahl, C., Boase, C., Lane, J. $\&$ Kaiser, A. (2003). Mosquitoes and their control. New York: Kluwer Academic/Plenum Publisher, pp. 493.

Bennick, A. (2002). Interaction between plant polyphenols with salivary proteins. Critical Review of Oral and Biological Medicine. 13: 184-196. https://doi.org/10.1177/154411130 201300208

Dusfour, I., Vontas, J., David J-P., Weetman D, Fonseca, D.M., Corbel, V., Raghavendra, K., Coulibaly, M.B., Martins, A.D., Kasai, S. et al. (2019). Management of insecticide resistance in the major Aedes vectors of arboviruses: Advances and challenges. PLoS Neglected Tropical Diseases 13: e0007615. https://doi.org/10.1371/journal. pntd.0007615

Elumalai, K., Dhanasekaran, S., Anandan, A., Krishnappa, K., Gokulakrishnan, J. \& Elangovan, A. (2012). Larvicidal, ovicidal and pupicidal activity of Eranthemumroseum (Vahl) R. BR. against malarial vector mosquito, Anopheles stephensi (liston) (Diptera: Culicidae). International Journal of Current Agricultural Science 2: 28-33.

Frentiu, F.D. Walker, T. \& O' Neill, S.L. (2014). Biological control of dengue and Wolbachia-based strategies. In: Dengue and Dengue Hemorrhagic Fever, Gubler, D.J. (editor) 2nd Edition. Oxford: CABI, pp. 537-547.

Ghosh, A., Chowdhury, N. \& Chandra, G. (2012). Plant extracts as potential mosquito larvicides. Indian Journal of Medical Research 135: 581-598.

Guo, X.D., Ma, Y.J., Parry, J., Gao, J.M., Yu, L.L. \& Wang, M. (2011). Phenolics content and antioxidant activity of tartary buckwheat from different locations. Molecules 16: 98509867. https://doi.org/10.3390/molecules16129850

Hasan, H.A., Jaal, Z., Ranson, H. \& McCall, P. (2016). Pyrethroid and organophosphate susceptibility status of Aedes aegypti (Linnaeus) and Aedes albopictus (Skuse) in Penang, Malaysia. International Journal of Entomological Research 3: 91-95.

Hussein, G., Rasul, A., Anwar, H., Aziz, N., Razzaq, A., Wei, W., Ali, M., Li, J. \& Li, X. (2018). Role of plant derived alkaloids and their mechanism in neurodegenerative disorders. International Journal of Biological Sciences 14: 341-357. https://doi.org/10.7150/ijbs.23247

Ishak, A.R., Dom, N.C., Hussain, H. \& Sabri, N.H. (2014). Biolarvacidal potential of Ipomoea cairica extracts against key dengue vectors. Procedia-Social and Behavioral Sciences 153: 180-188. https://doi.org/10.1016/j.sbspro. 2014.10.052

Kishore, G., Ranjan, S., Pandey, A. \& Gupta, S. (2010). Influence of altitudinal variation on the antioxidant potential of tartar buckwheat of western Himalaya. Food Science and Biotechnology 19: 1355-1363. https://doi.org/10.1007/s10068010-0193-9

Liu, X., Li, J., Guo, W., Li, R., Zhao, D. \& Li, X. (2014). A new type I peritrophic membrane protein from larval Holotrichia oblita (Coleoptera: Melolonthidae) binds to chitin. International Journal of Molecular Sciences 15: 6831-6842. https://doi.org/10.3390/ijms15046831

Liu, Y., Chen, P., Zhou, M., Wang, T., Fang, S., Shang, X. \& Fu, X. (2018). Geographic variation in the chemical composition and antioxidant properties of phenolic compounds from Cyclocarya paliurus (Batal) Iljinskaja leaves. Molecules 23: 2440-2451. https://doi.org/10.3390/molecules23102440 
Meira, M., Silva, E.P.D., David, J.M. \& David, J.P. (2012). Review of the genus Ipomoea: traditional uses, chemistry and biological activities. Revista Brasileira de Farmacognosia 22: 682-713. https://doi.org/10.1590/S0102-695X2012005000025

Mohiddin, A., Jaal, Z., Lasim, A.M., Dieng, H. \& Zuharah, W.F. (2015). Assessing dengue outbreak areas using vector surveillance in north east district, Penang Island, Malaysia. Asian Pacific Journal of Tropical Disease 5: 869-876. https://doi.org/10.1016/S2222-1808(15)60947-1

Muñoz, I.G., Schilman, P.E. \& Barrozo, R.B. (2020). Impact of alkaloids in food consumption, metabolism and survival in a blood-sucking insect. Scientific Reports 10: 9443-9452. https://doi.org/10.1038/s41598-020-65932-y

Ralte, V. (2014). Evaluation of phytochemical contents of Ipomoea cairica (L) Sweet - a qualitative approach. Science Vision 14: 145-151.

Rathod, S.S. \& Rathod, V.K. (2014). Extraction of piperine from Piper longum using ultrasound. Industrial Crops and Products 58: 259-264. https://doi.org/10.1016/j.indcrop.2014. 03.040

Rattan, R.S. (2010). Mechanism of action of insecticidal secondary metabolites of plant origin. Crop Protection 29: 913-920. https://doi.org/10.1016/j.cropro.2010.05.008

Rawani, A., Ghosh, A. \& Chandra, G. (2010). Mosquito larvicidal activities of Solanum nigrum L. leaf extract against Culex quinquefasciatus Say. Parasitology Research 107: 1235-1240. https://doi.org/10.1007/s00436-010-1993-9

Ritchie, S.A. (2014). 24 Dengue vector bionomics: Why Aedes aegypti is such a good vector. In: Dengue and Dengue Hemorrhagic Fever, Gubler, D.J., Ooi, E.E., Vasudevan, S. \& Farrar, J. (editors). Oxfordshire: CABI, pp. 455-480.
Samuel, L., Muthukumaran, R.B., Gurusubramanian, G. \& Senthilkumar, N. (2014). Larvicidal activity of Ipomoea cairica (L.) sweet and Ageratina adenophora (Spreng.) King \& H. Rob. plant extracts against arboviral and filarial vector, Culex quinquefasciatus Say (Diptera: Culicidae). Experimental Parasitology 141: 112-121. https://doi.org/10.1016/j.exppara. 2014.03.020

Sumayyah, A., Fadzly, N. \& Zuharah, W.F. (2016). Current observation on Aedes mosquitoes: A survey on implication of dengue infection, human lifestyle and preventive measure among Malaysia resident in urban and suburban areas. Asian Pacific Journal of Tropical Disease 6: 841849. https://doi.org/10.1016/S2222-1808(16)61143-X

Thiagaletchumi, M., Zuharah, W.F., Ahbirami, R., Fadzly, N., Dieng, H., Ahmad, A.H. \& AbuBakar, S. (2014). Assessment of residual bio-efficacy and persistence of Ipomoea cairica plant extract against Culex quinquefasciatus Say mosquito. Tropical Biomedicine 31: 466-476.

Thomas, T.G., Rao, S. \& Lal, S. (2004). Mosquito larvicidal properties of essential oil of an indigenous plant, Ipomoea cairica Linn. Japanese Journal of Infectious Diseases 57: 176177.

World Health Organization (WHO) (2005). Guidelines for laboratory and field testing of mosquito larvicides. Geneva: World Health Organization, pp. 8-11.

World Health Organization (WHO). (2009). Dengue guidelines for diagnosis treatment, prevention. 